\title{
Las cooperativas ante la crisis económica
}

\author{
Javier Divar Garteiz-Aurrecoa \\ Universidad de Deusto
}

Recibido: $\quad$ 02.06.10

Aceptado: 28.06 .10

Sumario: 1. Participación y cooperativismo. 2. Uniones Empresariales Cooperativas. 3. Capital y Cooperativas. 4. Sacrificios laborales y Cooperativas. 5. Radicación de las Cooperativas. 6. Cooperativas e Innovación. 7. Asepsia Cooperativa.

Resumen: Las Cooperativas están especialmente preparadas ante las crisis económicas, puesto que su estructura participativa permite el esfuerzo común de sus partícipes para afrontar las adversidades e incentivar la innovación, a más de que las uniones tradicionales entre ellas facilitan las sinergias colectivas de sus grupos societarios. Complementariamente su falta de lucrativismo permite los sacrificios laborales de sus socios, que además radican a estas sociedades con su entorno y les imponen la operatividad ante cualquier situación política.

Palabras Clave: Crisis. Cooperativas. Grupos. Innovación. Radicación.

Abstract: Cooperatives are especially prepared to face up to economic crises, since their participatory structure allows their members to join efforts to face setbacks and promote innovation. In addition, they are non-profit associations, which enables their members to make work sacrifices as they are also deeply rooted in their local environment and are required operational capacity when faced with any political situation.

Key words: Crisis. Cooperatives. Groupp. Innovation. Localisation. 


\section{Participación y cooperativismo}

Las cooperativas están basadas en la unión solidaria de sus socios para afrontar la adversidad, siendo ésta la causa de su origen y desarrollo desde los trabajos comunitarios del llamado precooperativismo hasta el mutualismo, antecedente del cooperativismo reglado del siglo XIX.

Por esa causa salvífica de los desamparados, el cooperativismo tiene su entronque fundador con los movimientos religiosos reformistas y muy especialmente con el primer cuaquerismo del holandés Peter Cornelius Plockboy, llamado con toda justicia el «Patriarca de la Cooperación», puesto que sobre la misma base de las comunidades cuáqueras (las «Sociedades de Amigos») para la mutua ayuda, a imagen de los primeros cristianos, teorizó sobre las «Repúblicas de la Cooperación» en un panfleto que escribió en 1659, resumido como «Ensayo para la felicidad de los pobres» (su título completo era «Ensayo sobre un proceso que haga felices a los pobres de esta nación y a los de otros pueblos, consistente en reunir cierto número de hombres competentes en reducida asociación económica, o pequeña república, en la cual cada uno conserve su propiedad y pueda, sin necesidad de acudir a la fuerza, ser empleado en la categoría de trabajo para la cual tenga más capacidad»).

Sobre el ideario de Plockboy, que el mismo llevó a la práctica fundando en 1664 en Manhattan una colonia agroindustrial (que por cierto, fue disuelta para evitar su «mal ejemplo» por orden directa del Gobernador inglés de la Colonia), se constituyeron más tarde los «Pueblos de la Cooperación» del galés Robert Owen (1771-1858) y los famosos «Falansterios» del francés Charles Fourier (1772-1837).

En los mismos Estatutos originarios de Rochdale, del 21 de diciembre de 1844, tenidos como modelos del cooperativismo moderno, como reglas jurídicas primeras, se dice en su primer expositivo que su intención es «el establecimiento de una colonia que se baste a sí misma y en la que se unirán los intereses, o bien prestará ayuda a otras sociedades para establecer colonias de esa clase».

Esa idea fundacional del cooperativismo como ente de unión frente a las dificultades, de grupo de participación para controlar el propio destino, sigue siendo la causa jurídica de sus sociedades, aunque el paso del tiempo haya emborronado su visión en algunos casos (de mero utilitarismo de la forma cooperativa, en ocasiones incluso contra su propia naturaleza).

Pero en esencia las cooperativas siguen hoy en día siendo la cumplimentación del viejo sueño utópico de la participación de los trabajadores en la economía, autogestionando por medio de ellas su trabajo, su consumo, su vivienda. 
Como dijo el filósofo López Aranguren «encauzan esa nueva evolución pacífica de la participación». Y a diferencia que las sociedades capitalistas, que establecen una comunidad dominante que conforman los aportantes de capital, y otra subordinada, conformada por sus propios trabajadores, las Cooperativas suponen la democracia del trabajo, evitando lo que Charles Levinson llamó «hostilidad peligrosa entre los empleados y la empresa», o lo que Giancarlo Moro definió [refiriéndose a la empresa] como "comunidad federal, formada por dos comunidades diferentes».

Las cooperativas están "seleccionadas por la evolución natural» de las especies económicas como empresas dotadas frente a las crisis, frente a las adversidades económicas, puesto que nacieron en ese medio natural y llevan siglos de supervivencia en el mismo. Está en su ADN la lucha por la superación de las dificultades, no son empresas débiles que sucumben fácilmente ante la hostilidad de las crisis que producen los ciclos económicos.

Y la fuerza íntima, alma de esas fortalezas, radica en la participación de sus miembros en la vida de la cooperativa, puesto que la integración en la empresa "como imperativo democrático» (en palabras tomadas de Fabricio Barbaso) supone una sinergia que pone en valor el "capital humano», el mayor activo que tienen las empresas, aunque algunas no parecen saberlo.

Pero en las cooperativas ese valor endógeno supone la circulación interna de la información empresarial, de manera que el saber aumenta el compromiso, sobre todo en los momentos difíciles. Los problemas no son sólo de la gerencia, todos están en el conocimiento de la evolución de las cosas y podrán aportar sus ideas y esfuerzos coordinados para el bien colectivo.

Pero sobre todo, la participación en la empresa o democracia empresarial se manifiesta en el voto con el que los socios cooperativos pueden censurar desde el conocimiento diario la gestión de los dirigentes, renovarlos o revocarlos, aprobar las cuentas, aplicar los resultados y, en fin, actuar como ciudadanos responsables de una «polis» de la que son miembros en su integridad. No están en el «idiotós» de los apartados de la vida del común, como sucede en otros tipos de compañías mercantiles, en las que la falta de participación de sus trabajadores produce el desinterés y la desconfianza de los mismos hacia una dirección lejana y engreída.

Por ello en las cooperativas la participación de sus miembros es su fuerza endógena, como queda dicho, que les permite afrontar las crisis con un ánimo que deriva del íntimo interés de sus socios en continuar el camino a pesar de las tormentas económicas de cada momento. Y como tantas veces se ha dicho, el interés mueve el mundo. 


\section{Uniones Empresariales Cooperativas}

Debido a su cultura solidaria las cooperativas tienen una larga historia de ayuda mutua entre las mismas, cultura que ha producido un sinfín de instituciones de alianza entre las cooperativas, cual son las uniones, corporaciones, integraciones de segundo y ulteriores grados, federaciones, confederaciones, etc.

Algunas han tenido un carácter "político» de representación frente a las Administraciones públicas o para la creación de estructuras de poder, caso de las federaciones y confederaciones (entes que se rigen por la figura piramidal que sigue el viejo principio jurídico que dice que «las personas se asocian, las asociaciones se federan y las federaciones se confederan»).

Otras implican figuras jurídicas de concentración empresarial, caso de las cooperativas de segundo y ulteriores grados y las agrupaciones y corporaciones, es decir, suponen obligaciones societarias estables, lo que implica una soberanía compartida de carácter económico. Es lo que Gide llamó «un desarrollo de la solidaridad entre cooperativas». Sus precursoras fueron las Uniones (CWS) inglesas y escocesas, pero las formulaciones jurídicas son variables dependiendo de cada legislación aplicable.

Implican la fuerza exógena de la participación cooperativa y su consecuencia es un corporativismo (directamente "darse cuerpo o tomar cuerpo») protector de las cooperativas ante las dificultades económicas, por lo que en tiempos de crisis esas alianzas entre cooperativas deben ser especialmente consideradas como instrumentos de autoayuda entre ellas.

Además del clásico federalismo cooperativo y de las uniones empresariales, deben potenciarse las meras alianzas económicas, supongan o no un convenio de tipo contractual. Es el caso de los aprovisionamientos entre cooperativas, la adquisición por las de consumo de bienes de las de producción, la contratación por las de vivienda de gremios organizados en forma cooperativa, la utilización por todas de las de servicios (de asesoría, gestión, etc), la apertura de líneas específicas de crédito, y en general, utilizar en la medida de lo posible los bienes y servicios de otras cooperativas, creando una interactividad beneficiosa para el conjunto del movimiento, dada la sintonía de valores y de necesidades.

Esas relaciones de autoayuda entre cooperativas, ya históricas entre ellas, resultan ser sin duda alguna una fortaleza de las sociedades cooperativas frente a las crisis económicas generales, propias de los ciclos del sistema económico, que por su reiteración suponen una de las debilidades del mismo.

El resaltamiento de la importancia económica de las relaciones intercooperativas no es por ello nada nuevo. Ya en la Conferencia Eco- 
nómica Mundial celebrada en Ginebra en mayo de 1927 se aprobó una resolución al efecto, relativa a las mejoras económicas del medio agrario, cuyo extracto dice:

A. Los agricultores de los distintos países están empeñados en mejorar sus condiciones de vida, y contribuyen al mismo tiempo al bienestar general, recurriendo en una medida cada vez mayor a la unión cooperativista en todas sus formas: cooperativas de compras para cubrir las necesidades profesionales o domésticas; cooperativas de ventas para la colocación ordenada de sus productos; cooperativas de productores para las operaciones entre producción y venta; cooperativas de crédito para la obtención de capital.

Así las instituciones cooperativistas aumentan el poder adquisitivo de los agricultores como productores y consumidores. Simultáneamente fomentan el progreso económico aumentando la capacidad de rendimiento y mejorando los productos, así como también por el hecho de posibilitar un aprovechamiento total de los frutos. Finalmente contribuyen a conquistar mercados por medio de métodos que reducen al mínimo los gastos de distribución.

B. Las cooperativas agrarias contribuirán a una mayor racionalización de la economía en la medida en que aumenten la multiplicidad de sus relaciones con las cooperativas de consumo. Las relaciones directas entre productores y consumidores y sus respectivas organizaciones eliminan a los intermediarios superfluos y conducen, si se extienden en debida forma, a una estructura ventajosa de los precios para ambas partes. Las cooperativas de productores y consumidores llegan a apreciar el valor de un intercambio comercial directo que responda a sus principios comunes. Los esfuerzos por llevar a cabo este plan en la práctica, podría apoyarlos el agro, produciendo mercaderías de determinadas y homogéneas condiciones; los consumidores, decidiéndose a comprar, dentro de lo posible, los productos agrarios de las cooperativas de los productores rurales; las autoridades estatales y públicas, apoyando el movimiento cooperativista mediante la instalación de cátedras en universidades u otras instituciones científicas, el ofrecimiento de cursos oficiales sobre el movimiento cooperativista y con una política impositiva que se abstenga de toda medida perjudicial para las cooperativas.

Una colaboración eficiente, si fuera necesario en forma de empresas comunes, se logrará más fácilmente si las cooperativas 
de productores y consumidores de los distintos países se reúnen en comisiones económicas comunes e internacionales.

C. Los convenios internacionales entre cooperativas agrarias sobre determinados productos podrán coadyuvar al saneamiento de los mercados, a la regulación de la producción y a la formación de precios estables que consideren, de una manera satisfactoria, el equilibrio entre la producción y el consumo.

D. Para que tales convenios internacionales puedan cumplir con sus designios, se requiere una colaboración confiada con las cooperativas de consumo nacionales e internacionales, sobre la base de relaciones comerciales regulares y de contratos a largo plazo.

Karl Grünewald, en un trabajo sobre el intercooperativismo alemán, preparado a cuenta del Ministerio de Alimentación, Agricultura y Bosques de Nordrhein-Westfalen (publicado en español con el título «Relaciones económicas inter-cooperativas», por Intercoop, Buenos Aires, en 1967), dice en sus consideraciones finales: «El resumen de los resultados de nuestra investigación no justifica ni esperanzas demasiado exageradas para el futuro, ni una apreciación desalentadora de los resultados obtenidos en el pasado y presente. En el transcurso de nuestro estudio pudimos demostrar que existen no solo buenos propósitos, sino también indicios muy serios de una colaboración intercooperativa».

Y más adelante añade: "Las exposiciones que anteceden han puesto de relieve las dificultades de distinta índole que pueden oponerse a la colaboración entre las cooperativas agrarias y las de consumo. Por otra parte se ha podido demostrar que, a pesar de todos los obstáculos y escabrosidades, existen caminos que conducen a una meta deseable para ambas partes, si predominan la buena inteligencia, la mutua comprensión y un genuino espíritu cooperativista.

Destacamos además, detalladamente, las ventajas para la economía nacional en general, que surgirían de una intensificación del intercambio intercooperativo directo. El objetivo principal de la colaboración intercooperativa, o sea el de lograr, por medio de una mejor organización de los procesos de producción y elaboración y una concentración más racional de la distribución (en última instancia el de lograr un aumento del ingreso real y por ende del producto social), es una de las preocupaciones primordiales de la política económica actual. Así, la colaboración cooperativista contribuye a crear un orden más racional del mercado que, sobre la base de relaciones estables, permitirá llegar a una planificación previsora con reducción de riesgos y costos, aumen- 
tos de productividad y una distribución económicamente favorable del producto social».

Por esa «vocación solidaria» se ha dicho, con extensión general a toda la llamada Economía Social, que la misma «pone en evidencia un modelo socioeconómico más socialmente equilibrado e innovador que no tiene vocación de actuar aislado, sino como parte integral del conjunto de la economía» (Juan Antonio Pedreño Frutos, Presidente de la Confederación Empresarial Española de la Economía Social, CEPES, en «La Economía Social en España-2008/2009. Madrid). Y aún, que «la Economía Social está llamada a ser una pieza fundamental en el desarrollo del nuevo modelo productivo» (José Luis Rodríguez Zapatero, Presidente del Gobierno de España, en la misma publicación, página 10).

\section{Capital y Cooperativas}

A diferencia de las sociedades de capital, significadamente en el caso de las grandes sociedades por acciones, las cooperativas no tienen como finalidad última el ánimo de lucro, puesto que no tienen que retribuir al capital. En las sociedades capitalistas la cuenta de resultados termina siendo una obsesión, lógica puesto que si no tiene un saldo positivo no se pueden dotar dividendos ni reservas, y su noticia puede desanimar la inversión bursátil, siempre volátil («el dinero tiene patas» y corre a comer a los mejores pesebres).

En las cooperativas en cambio, aunque el resultado del ejercicio también es muy importante (y a nadie le amarga un dulce), ante las adversidades puede llegarse al límite de la resistencia, ya que el ánimo cooperativo es el cumplimiento del objeto societario (el trabajo en las de producción, el consumo adecuado en las de abastecimiento, el acceso a la vivienda, a una enseñanza adecuada, etc.).

Esa diferencia finalística entre los tipos societarios permite a las cooperativas mantenerse en las adversidades aun sin beneficios, siempre que no se llegue a los límites económicos de su disolución, porque sus socios preferirán resistir, por ejemplo manteniendo el empleo en las de trabajo asociado. En cambio, en las sociedades capitalistas las crisis provocan de inmediato desinversiones y pérdida de empleo, porque su finalidad económica es el lucro, finalidad perdida de raíz si la cuenta de resultados no arroja saldos positivos.

Por la condición propia de su objeto las cooperativas pueden permanecer durante largo tiempo sin beneficios, algo impensable por ser contrario a su misma lógica económica en las sociedades capitalistas, 
e incluso pueden llegar las cooperativas en tiempos de dificultades a acordar dotaciones económicas de sostenimiento, como el incremento o establecimiento de cuotas extraordinarias a tal fin, o el aval por los propios socios de crédito mercantil para la sociedad (mejor obligarse que perder el empleo, por ejemplo).

Por esta razón del muy diferente objetivo económico, las cooperativas están especialmente dotadas por su propia naturaleza jurídica, a resistir ante los malos tiempos económicos.

\section{Sacrificios laborales y Cooperativas}

En directa derivación de lo visto en el punto anterior, las cooperativas están en posición privilegiada, en comparación con las restantes sociedades mercantiles, para pedir a sus socios trabajadores y de trabajo sacrificios laborales, incluidos los que directamente suponen una pérdida de ingresos.

Aunque en todo tipo de empresas los trabajadores están dispuestos a sacrificarse en los momentos de dificultades de las empresas para las que trabajan, máxime en el caso de las crisis generalizadas, que obstaculizan las alternativas individuales, en las cooperativas esto es significativamente más notorio, como la práctica nos enseña.

Esa peculiar posición de los cooperativistas proviene de una parte de su mejor información sobre la marcha de la empresa, y de otra de que el trabajador cooperativo suele considerar la empresa como suya, como una sociedad de la que es titular y por ello responsable de la misma.

Es destacable en este punto que en las cooperativas los propios socios toman las decisiones de recorte que les perjudican personalmente, claro está que en beneficio del colectivo, de manera que para la manutención del empleo se responsabilizan de las decisiones empresariales limitativas, así que en ellas no puede hablarse en puridad de imposiciones de la dirección.

Por lo tanto resulta habitual ante las crisis ver como en las cooperativas se aumentan las jornadas sin retribuciones complementarias, se acuerdan en sus asambleas la pérdida de pagas extraordinarias, se recortan los ingresos periódicos ordinarios, se prescinde de festivos y aún de vacaciones, se anulan actualizaciones del capital y se acuerda el destino a reservas de todo el resultado económico excedente, entre otras medidas extraordinarias.

Todo ello en decisiones asamblearias que suponen, a diferencia del resto de sociedades, que los cooperativistas se autocongelan sus be- 
neficios empresariales, sin que ello derive en conflictividad colectiva (aunque en buena lógica no es un plato de gusto, como suele decirse), puesto que el voto mayoritario desactiva cualquier vindicación.

La participación de sus socios trabajadores y de trabajo, unida a la falta del imperativo económico del beneficio, sustituido por el mantenimiento del objeto cooperativizado, terminan estableciendo que las cooperativas se sitúen a la vanguardia de las sociedades económicas en la resistencia frente a las crisis, como modelos de organizaciones empresariales para afrontarla, aunque su imitación es imposible si no se participa de sus valores y principios.

\section{Radicación de las Cooperativas}

Las cooperativas están por su propia naturaleza muy radicadas en su ámbito territorial, puesto que asocian trabajo (las de producción), consumo, vivienda, enseñanza, etc., con titulares vecinos de las áreas geográficas de su inmediatez económica, como corresponde a su propia lógica.

Por ello la forma cooperativa es en sí misma una fórmula que dificulta las deslocalizaciones empresariales, al no ser razonable que los socios de las cooperativas voten en contra de sus intereses, que también están radicados en su ámbito, a diferencia que sucede con los meros aportantes de capitales.

Para las cooperativas la deslocalización no es en absoluto una oportunidad competitiva, como sostuvo al respecto el Círculo de Empresarios en su informe "España ante el nuevo paradigma de la competitividad», del año 2005, en el que se argumenta que la deslocalización debe verse como un proceso natural que puede servir para mejorar la competitividad.

Poco antes, en 2004, la profesora Sara González Fernández, de la Cátedra Jean Monet de la Universidad Complutense, en un documento titulado "La deslocalización de las empresas europeas hacia Latino América como una estrategia comercial», desvela la importancia de las diferencias de los costes laborales en estos procesos. Así, con datos del año 2003, acredita que ante un porcentaje 100 para España, el coste laboral en U.S.A. era de 200,7; en Puerto Rico de 83,4; en México de 43,7; en Argentina de 35,6; en Brasil y Venezuela de 35; en Chile de 30,4; la media en Centroamérica de 26,2; en Perú de 17,2 y en Colombia de 14,7.

Así que tales razones son las que mejor explican la llamada «exportación de empleos», que sólo para U.S.A. se calculan en unos 4 millones a causa de deslocalizaciones de sus empresas (Informe Forrester). 
Añadidas a otra «ventaja competitiva», las diferencias de fiscalidad, que pone también de relieve el Informe Arthuis, de 1993.

Sin embargo, para economías de desarrollo medio, como es el caso de la española, la imposibilidad de competir con naciones cuya mano de obra es de muy alta cualificación técnica, también es problemática en producciones avanzadas. Como ponen de relieve Rafael Myro y Carlos Manuel Fernández-Otheo, en su artículo «Deslocalización de empresas en España» (Universidad Complutense, 2005 ), «para economías de desarrollo medio-alto, como la española, las amenazas de deslocalización no vienen sólo de los países más atrasados, sino también de los más avanzados, con mano de obra más cualificada y mayores economías de aglomeración».

Analizando la doble deslocalización, la que aprovecha los salarios más bajos y la que se basa en una mano de obra más cualificada que incrementa el valor añadido de los productos y servicios, un estudio de Pricewaterhouse Cooper en España, del año 2005, procedente de una encuesta de opinión sobre la materia realizada entre expertos empresariales, muestra que el 77,3 \% considera que el riesgo de deslocalización de empresas en España es alto o muy alto.

En concreto, en dicho informe de Pricewaterhouse Cooper se indica que por cause de los costes laborales españoles el riesgo de deslocalización de empresas en España es muy alto, para la opinión del 83\% de los expertos consultados.

Por lo que respecta a la falta de valor añadido por deficiencias de implantación tecnológica, el riesgo de deslocalización es alto a criterio del 51,4 de los expertos consultados.

Para combatir esos riesgos opina el $70 \%$ de esos expertos que es imprescindible atender a dos variables:

1. a) Aumentar la dotación (formación ) del capital humano en las empresas españolas.

2. $\left.{ }^{a}\right)$ Incrementar la diversificación de la producción, que se considera muy anclada en objetivos empresariales unidireccionales.

Los propios agentes laborales han analizado con preocupación lógica la pérdida de puestos de trabajo que las deslocalizaciones suelen suponer, como principal sangría social para los países que la sufren o están en alto riesgo de padecer, como es el caso de España. En este sentido puede destacarse por su actualidad e interés el Seminario de Girona del Centro de Estudios Europeos para la Formación de los Trabajadores (celebrado en mayo de 2009).

El título de este Seminario ya es muy significativo: "Causas y objetivos de la deslocalización de empresas. El futuro de las empresas y de 
los trabajadores por la deslocalización hacia los nuevos mercados emergentes». En él se consensuaron varias "constataciones», entre ellas la que afirma que «la globalización se ha expandido sin ningún tipo de contrapesos sociales que hubiesen servido de control social de este fenómeno económico».

Como alternativas ante la deslocalización propone el Seminario de Girona las siguientes:

1. a) Aumentar las dotaciones económicas y los esfuerzos de fomento de la Investigación aplicada, incrementando el número de patentes de invención y aminorando paulatinamente las importaciones tecnológicas.

2. $\left.{ }^{a}\right)$ Aprovechar las líneas de Innovación por parte de todo el entramado empresarial, con el apoyo de las instituciones públicas y privadas, así como su aceptación por las diferentes líneas docentes y singularmente por las de las Universidades.

3. $\left.{ }^{a}\right)$ Apostar de nuevo, de forma reiterada y constante, por una política general y concertada a favor del Desarrollo económico, volviendo al fomento ordenado de unas líneas desarrollistas a favor de la creación de empresas y la consecuente creación de nuevos empleos en sectores y subsectores preferentes (para que los esfuerzos sean canalizados muy singularmente sobre los mismos).

4. $\left.{ }^{a}\right)$ Seguir insistiendo en una adecuada Formación Profesional, que canalice estas formaciones a las necesidades de las empresas, publicitando además entre la población el prestigio de las mismas, de manera que la utilidad pública de la educación técnica beneficie a las empresas y también a los alumnos, para que no queden frustrados en sus expectativas laborales ni desconsiderados socialmente como titulados de menor cualificación.

\section{Innovación y Cooperativas}

La innovación es vital (en sentido directo) para todo instituto social, máxime para la empresa, que vive en competencia en un medio difícil para la supervivencia, como son los mercados abiertos actuales.

El mismo progreso "consiste en renovarse», como dijo Miguel de Unamuno, por lo que la falta de renovación supone la pérdida de aire para la empresa, su pérdida de valor añadido, su muerte económica ante la pérdida de competitividad.

Muy gráficamente lo argumentaba Max Planck, el llamado «Padre de la Física Cuántica», que sostenía que los oponentes de la moderni- 
dad y la innovación «se van muriendo, siendo sucedidos por jóvenes innovadores por naturaleza».

A diferencia que la Investigación y el Desarrollo (I+D), la innovación no requiere del mantenimiento de costosos equipos ni de complejos sistemas organizativos, sino de una actitud en la empresa de aceptación y aplicación de las ideas inventivas y novedosas de todos sus partícipes (con inteligente modestia, ya que del más humilde se puede aprender mucho, por lo que también en este campo la soberbia y el engreimiento son malos consejeros).

La innovación la podemos definir como la aplicación de ideas inventivas en las empresas. Por ello requiere una actitud previa participativa, de aprovechamiento de toda idea novedosa, al menos para un análisis previo de utilidad para su posible aplicabilidad práctica.

La innovación puede referirse a sistemas, a productos y a servicios. En todo cabe la innovación y en relación a todas las empresas. Por ello supone una posición de mejora para grandes sociedades, medianas o pequeñas.

Sobre todo en las pequeñas y medianas empresas, que no pueden permitirse una costosa investigación de mejora de sus líneas de producción o de sus productos, la innovación es vital. Una idea de cualquiera de sus miembros puede ser para ellas motivo de supervivencia o de despegue.

La forma de presentación de un producto, la mejora de un diseño, un toque publicitario que mueva la simpatía de los consumidores, un almacenamiento que facilite la conservación, una relación acorde con el ambiente,... cualquier novación aplicada a la empresa, su organización, sus productos, sus servicios, sus relaciones con los clientes o proveedores, puede ser causa de un valor empresarial que facilite el mantenimiento y la vitalidad de la empresa.

En las cooperativas su propia cultura participativa facilita su permanente creatividad, al establecerse en ellas una intervención organizada, incluso como derecho del socio por su propio régimen jurídico.

En las cooperativas más grandes, sin embargo de lo indicado, es necesario articular el sistema para el aprovechamiento de la creatividad innovadora de sus miembros, ya que en ellas la propia estructura hace que la participación no sea tan directa como en las pequeñas.

Y ello por que el mismo empleo puede ser tributario de las ideas innovadoras y creativas. Como dijo el editorial de la Revista «Trabajo y Unión» del grupo cooperativo de Mondragón (número de Octubre de 2008), si se quiere «cumplir la misión que nos hemos propuesto de generar empleo, preferentemente cooperativo, adecuado al desarrollo de nuestro entorno, la innovación es una necesidad perentoria». 
Con meridiana claridad Andoni García, Director del Polo Tecnológico Garaia, en la Revista Cuadernos de Economía Social (n. ${ }^{\circ}$ 4/2008), dice: "La respuesta [ante los nuevos retos empresariales y la crisis] no es más $1+D$, sino socializar la innovación y pasar a crear culturas innovadoras».

Esa cultura innovadora, que ahora se quiere incorporar a todo el tejido empresarial como medio de constante regeneración del mismo, como un rejuvenecimiento constante que permita la supervivencia de las pequeñas y medianas empresas, que no pueden participar de la tecnología de punta por su alto coste, es ya una tradición del sistema cooperativo.

La innovadora cultura cooperativista se ha extendido incluso al sistema organizativo y jurídico de sus sociedades, siendo adelantadas en el establecimiento de socios estatutarios, en los fondos sociales para la formación de sus miembros, en el capital variable y sus actualizaciones, en los órganos sociales complementarios, en la información constante de sus socios fuera de las Juntas, en la organización de uniones, corporaciones, consorcios, personalidades jurídicas de grados ulteriores, y una larga lista de innovaciones estructurales que han facilitado la flexibilidad de las cooperativas para su permanencia en los mercados, aun en condiciones extremas de muy difícil viabilidad económica.

\section{Asepsia del Cooperativismo}

Otra cualidad de las cooperativas procede de su larguísima tradición de mantenimiento ante medios políticos y legales poco favorables y aún hostiles, lo que las ha hecho muy resistentes frente a la adversidad y por ello tienen grandes fortalezas frente a las crisis, puesto que históricamente son sociedades de «resistentes» ante autoridades de toda condición.

El caso de España es precisamente un ejemplo paradigmático de ello. Mientras en otras naciones europeas se iniciaba la regulación jurídica de las sociedades cooperativas en la segunda mitad del siglo XIX, caso del Reino Unido, Alemania, Francia, Portugal,...en España a pesar del reconocimiento mercantilista de las cooperativas y las mutuas de seguros a prima fija en el artículo 124 del Código de Comercio, ni éste desarrollaba normativa alguna aplicable, ni lo hacía la legislación especial.

Así las cosas, las cooperativas actuaron a finales del XIX en España como sociedades civiles o como asociaciones de derecho privado, desde la ley de Asociaciones de 1887. A comienzos del xx las cooperativas agrarias pasan a constituirse, en buen número, como sindicatos agrarios, aprovechando la correspondiente legislación, llegándose 
así hasta 1931, año en que en la II. ${ }^{a}$ República Española se promulga la primera ley de cooperativas de España (por cierto, poco mercantilista por su acendrado asamblearismo, corregido por la ley catalana de 1934).

Pero, como es bien sabido, la Guerra Civil termina con todo ello (ya en 1938, en el llamado «bando nacional», se promulgaron las normas derogatorias de la legislación republicana), estableciéndose después, desde la ley de 1942, un «cooperativismo sindicalista» controlador del movimiento cooperativista.

El camino del cooperativismo en libertad no se va a retomar en España hasta la actual Constitución de 1978, cuyo artículo 129.2 dice textualmente: "Los poderes públicos promoverán eficazmente las diversas formas de participación en la empresa y fomentarán, mediante una legislación adecuada, las sociedades cooperativas. También establecerán los medios que faciliten el acceso de los trabajadores a la propiedad de los medios de producción».

Pero lo cierto es que esta historia de la evolución del cooperativismo en España pese a todas las dificultades (que han sido muchas), es un ejemplo muy claro del desarrollo de las cooperativas a pesar del medio hostil, en el que nació incluso el potente "Cooperativismo de Mondragón» (MCC, siglas de Mondragón Corporación Cooperativa).

Esos ejemplos de la vida de las cooperativas ante medios políticos, legislativos y económicos hostiles, son muy numerosos en todo el mundo y a lo largo de la historia, por lo que puede hablarse de una asepsia cooperativa resistente ante estas «enfermedades» sociales.

Por ello no es impropio hablar de un distanciamiento preventivo del cooperativismo con respecto a los idearios y sistemas políticos, que en muchas ocasiones se han aprovechado de su buena fe democrática (lo que por cierto se corresponde con su «iluso utopismo»).

Aparte del distanciamiento de los gobiernos «burgueses» en relación al cooperativismo, el caso más señalado de utilización partidista de las cooperativas por los intereses políticos se ha producido históricamente en relación a los gobiernos comunistas.

Ya Lenin en un artículo redactado por él en el mes de Enero de 1923, poco antes de su fallecimiento, y que fue publicado por el diario Pravda el 25 de mayo de 1923, decía al respecto del uso por la Revolución de las cooperativas: "Dado que en nuestro país el poder del Estado se encuentra en manos de la clase obrera y que a este poder estatal pertenecen todos los medios de producción, sólo nos queda, en realidad, cumplir la tarea de organizar a la población en cooperativas».

Sólo se le escapaba un «pequeño detalle»: que las cooperativas son sociedades privadas, en las que sus miembros ejercen una democracia 
directa. La estatalización de las cooperativas supone una violación de su naturaleza jurídica, es decir, en puridad el ente resultante no es una cooperativa, sino un «monstruo jurídico público», lejano a los principios cooperativistas.

Algo semejante, en sentido contrario, que si se impone un régimen jurídico capitalista a las cooperativas, alterando también su naturaleza, lo que daría por resultado una sociedad mercantil lucrativista, con voto proporcional al capital suscrito y dividendos a su prorrata.

Lo que en realidad buscaba Lenin era la integración de los trabajadores por medio de las cooperativas, únicas asociaciones que no les producían rechazo, tras siglos de explotación y de humillaciones.

Por ello Lenin, como dice Diva Benevides Pinho, en su «Evolución del Pensamiento Cooperativista» (Intercoop. Buenos Aires, 1987, página 78), «critica a los militantes soviéticos que no comprenden la excepcional importancia de las cooperativas o que las subestiman, y afirma la necesidad de conceder una serie de ventajas económicas, financieras y bancarias a la organización de cooperativas y a la formación de cooperativistas».

En el mismo campo ideológico, «el timonel» de la China comunista Mao Tsé Tung, siguiendo la practicidad aprendida del leninismo, impulsó el apoyo a las cooperativas desde el Comité Central del Partido Comunista Chino.

Siguiendo con Diva Benevides Pinho: «En el mismo sentido, Mao Tsé Tung se habría preocupado por las ventajas de las cooperativas en el marco de la China socialista y, de cierta manera, por mostrar que es correcta la política de apoyo a las cooperativas adoptada por el Comité Central del PC».

Y continúa diciendo: "Así, en un Informe presentado a los Secretarios de los Comités Provinciales, Municipales y de las Regiones Autónomas, en la reunión del PC chino del 31 de julio de 1955, Mao citó datos sobre la intensa multiplicación de cooperativas agrícolas e insistió en la necesidad de velar por su consolidación y por la calidad de su producción».

Y concluye: «En suma, en los países socialistas, las cooperativas de producción han sido despojadas de su contenido doctrinario, y se integran, como técnica organizativa, en la doctrina adoptada por los respectivos Partidos Comunistas».

Este "cooperativismo político» ha sido instrumento de intereses opuestos, y así como la dictadura franquista creó legalmente en España "cooperativas sindicalistas», en la URSS y en la China comunista («los extremos se tocan», como dice la sabiduría popular) se terminaron creando «cooperativas del Estado». Ya el Comité Central del Par- 
tido Comunista de la URSS, en 1924, propuso al XIII Congreso del Partido una resolución colectiva reclamando que «la atención fundamental del Partido se centre en la agrupación de los pequeños productores en cooperativas, lo que debe desempeñar un gigantesco papel en la construcción del socialismo».

Así que las cooperativas han salido malparadas entre «tirios y troyanos», o como se dijo de los liberales en la Guerra Civil Española: «Resultaron depurados en ambas zonas».

Y aún con todo, los cooperativistas continuaron actuando como tales en "ambas zonas», a pesar de la legalidad imperante (pocas veces mejor dicho) o tal vez apartados de ella, puesto que como suele decirse «el cooperativismo se hace con cooperativistas», resistentes incluso a esas adversidades.

No ha faltado incluso una nación oficialmente denominada cooperativa: la República Cooperativa de la Guyana, tras la reforma constitucional que en la antigua Guayana Británica promovió en 1970 su presidente Linden Forbes Burnham.

El Presidente Burnham era hijo de un maestro de escuela que le educó en los valores morales, enviándole a Inglaterra para completar su formación. En el Reino Unido conoció la larga y meritoria historia del cooperativismo británico, que le deslumbró por su pedagogía social y su cultura solidaria, entendiendo que era la doctrina política adecuada para el desarrollo de su propio país.

Vuelto Burnham a la Guayana participó en la fundación del Partido del Congreso Nacional (PNC), con el que ganó las elecciones generales de 1968, tras la independencia del país en 1966.

Convertido en Presidente, Linden Forbes Burnham reformó la Constitución de Guyana en 1970, denominando oficialmente a la nación República Cooperativa de Guyana, siguiendo su viejo ideal de juventud. Para clarificar su idea de "república cooperativa», siguiendo los orígenes cuáqueros de los antiguos colonos holandeses del país, publicó una Declaración el 14 de Diciembre de 1974 en la que abogaba por un «socialismo cooperativista». En los primeros momentos el respaldo popular fue enorme, y en las elecciones de 1980 el partido de Burnham obtuvo el respaldo del $71 \%$ del voto electoral.

Pero la deriva del Presidente Burnham fue de un paulatino autoritarismo, sobre su posición de dominio político. Se empeñó en nacionalizar las antiguas empresas coloniales, buscándose así recelos y enemistades internacionales. Su respuesta fue la de acercarse a los países llamados «no alineados» y al régimen de Cuba, con lo que se enemistó con los EE.UU. Esa política terminó por empobrecer el país, y a la muerte de Burnham, el 6 de Agosto de 1985, la herencia que dejó fue 
una colosal deuda pública internacional (que en el año 2007 fue amortizada por el Banco Interamericano de Desarrollo, BID).

Todos estos ejemplos sirven para acreditar sobre los hechos probados que la política no le sienta bien al cooperativismo, que en cambio se muestra cómodo en su independencia, actuando con asepsia y pragmatismo en cualquier sistema, lo que es precisamente una causa de su resistente mantenimiento histórico.

Ello es debido a que el cooperativismo no es una ideología política partidista, sino una forma societaria económica, común a todos los que están acordes con ahondar en la participación en las empresas.

En esa asepsia el cooperativismo sintoniza, aunque con independencia intelectual, de posiciones humanistas, políticas y religiosas mantenidas por muchas personas en todo el mundo, como acredita la Alianza Cooperativa Internacional, nacida en el siglo XIX, y que con reputada ausencia de alineamientos políticos representa a más de 500 millones de cooperativistas de todo el orbe, miembros de diferentes religiones e ideologías políticas, cuyo denominador común es el cooperativismo, como movimiento económico y social universal.

Esa independencia ideológica, esa asepsia institucional, conforma una de las potencias de las cooperativas, que la pierden en cuanto se hacen partícipes de intereses ajenos, no santos para el cooperativismo, contaminantes de su naturaleza, que está probado que le producen daño.

Sin embargo, el 23 Congreso de la Alianza Cooperativa Internacional $(\mathrm{ACl})$, celebrado en Viena en 1966, bajo pretensiones de pragmatismo, decidió que las cooperativas utilicen su poder económico y político cuando convenga a su interés particular y a los del movimiento cooperativo en su conjunto.

Pero esa postura no ha sido siempre bien aceptada, como manifestó, entre otros muchos, el profesor de la Universidad de Marburg, Hans-Hünkner, que en su obra «Principios Cooperativos y Derecho Cooperativo» (Bonn, 1988), dice que internamente las cooperativas «debieran abstenerse de intervenir en las convicciones religiosas o políticas de sus miembros y evitar que sus reuniones sean transformadas en plataforma de lanzamiento de campañas políticas» (cita en la página 88).

Añadiendo textualmente que en sus relaciones externas «las sociedades cooperativas y el movimiento cooperativo en su conjunto, debieran intentar mantener su independencia frente a los partidos políticos y el gobierno; y deberían concentrar sus esfuerzos en la realización de sus propios programas económicos y sociales, a saber, trabajar en tanto que organizaciones democráticas de autoayuda que tienen por objeto la promoción de sus socios, y preservar su independencia política». 
Concluye Hans-Hünker que esa prohibición de participación política de las cooperativas puede ser determinada en su legislación especial, o bien, alternativamente, establecerse en ella que el objeto de las sociedades cooperativas es «la promoción de los intereses económicos de sus socios», de manera que las que tuvieran por objeto "actividades esencialmente políticas», debieran quedar excluidas del registro de cooperativas (citas en la página 89).

Por ello E.S. Bogardus («Principles of Cooperation: The Cooperative League of the U.S.A.», Chicago, 1964, página 19), sostiene que la neutralidad política y religiosa ha sido considerada como uno de los principios clásicos de la acción cooperativa, de las cooperativas como organizaciones económicas, que pueden debilitar su estructura al ocuparse de cuestiones no estrictamente económicas.

Pero también los modelos capitalistas han utilizado al cooperativismo como mera forma de empresa, trasvasando en ocasiones sus principios y valores como instrumentos de corrección de sus aristas más duras, renovaciones y puestas al día en las que el capitalismo tiene una prolongada experiencia, que viene ejerciendo con reconocida maestría.

Aquí podemos recordar a Bernard Lavergne, en su obra «El socialismo con rostro humano», publicada por Presses Universitaires de France, en 1971 (la edición española se publicó por Intercoop, en Buenos Aires). En el capítulo primero de la misma, bajo el título de "Los grandes trastornos recientes», dice Lavergne textualmente: "Siendo el capitalismo casi universalmente censurado, el problema crucial que se le plantea al hombre moderno es el de descubrir con qué estructura ha de reemplazar el orden capitalista. Trataremos de demostrar que el socialismo cooperativo tiene la eficacia del orden capitalista y libera al hombre de su actual servidumbre y de su alineación».

Pero lo cierto es que no se trata de demostrar nada, sino sólo de mostrar los caminos por los que puede discurrir la acción económica, eligiendo con libertad entre ellos. En esta intención la forma cooperativa es un tipo más de sociedad económica, que se propone en libertad mercantil, nunca una imposición ni un sistema único, puesto que ello está reñido con la democracia económica que el cooperativismo pretende, que depende además del momento histórico y de las circunstancias de cada lugar. Por ello el cooperativismo está en permanente evolución y hay varias vías al mismo, igual que sucede con el capitalismo.

Además, Bernard Lavergne cae en la misma falta de poner apellido político al cooperativismo, al llamarlo "socialismo cooperativo», lo que constituye un exceso que puede producir rechazos como todo partidismo. Verdaderamente lo que el cooperativismo supone es una par- 
ticipación en la propia empresa, es decir, una democracia cooperativa, parte de la democracia económica.

Como ya está dicho: "Así como el liberalismo es fuente ideológica del sistema capitalista y de la democracia política, la participación en la empresa es determinante de los principios de la democracia económica y ésta del orden democrático integral. Esa democracia económica no pasa solamente por la esencia de las sociedades cooperativas, sino por toda participación empresarial, bajo cualquier forma jurídica. Igualmente que el capitalismo no sólo se acredita por grandes sociedades anónimas, aunque es evidente que estas instrumentalizan la democracia capitalista, institucionalizan su sistema y sistematizan su normativa jurídica» (Javier Divar, «Globalización y Democracia», Dykinson, Madrid, 2005, pág. 73).

Por ello la cooperativa es un «modelo de organización social», como indica Gabriele Racugno en su obra «La Sociedad Cooperativa» (Sección IV-Tomo 9 del «Trattato di Diritto Comérciale», cita en la página 21), recogiendo una cita de A. Bassi («L'impresa societaria con scopo mutualistico», del «Manual de Derecho Comercial», bajo la coordinación de Vincenzo Buonocuore, en la página 397), «idóneo para corregir los desequilibrios del sistema económico capitalista».

\section{Conclusión}

Las cooperativas por su naturaleza de sociedades participadas y democráticas están muy preparadas para solventar las crisis económicas, puesto que sus miembros conocen bien la deriva de la compañía y están en posición de afrontar unidos las dificultades.

Además, como no precisan dotar al capital con dividendos, pueden sostenerse con sólo cumplimentar el objeto societario, de manera que su mantenimiento es ya un objetivo económico para ellas. Ello supone la priorización en las mismas de la conservación del empleo.

Consecuencia de lo antedicho es que los sacrificios laborales (por ejemplo el aumento de las jornadas de trabajo) o salariales (reducción de ingresos, renuncia de pagas extras, etc.) es mucho menos conflictivo que en otros tipos societarios, puesto que en las cooperativas estas decisiones son tomadas por los propios interesados, que además acceden a una información económica y contable directa.

Las mejoras procedentes de la innovación circulan con facilidad en ellas, precisamente como consecuencia de la participación directa de todos sus miembros en su estructura orgánica.

La larga tradición histórica de las cooperativas de conformar uniones y corporaciones facilita también en ellas las alianzas empre- 
sariales, de forma que pueden afrontar corporativamente las dificultades.

Las cooperativas están íntimamente radicadas en su medio geográfico natural, que es el de sus miembros, siendo así que estas sociedades no practican en lo esencial deslocalizaciones, puesto que ello sería contrario a su lógica económica, por lo que el interés social de su comunidad les es propio (como comienza diciendo textualmente el artículo 137 de la Ley Vasca de Cooperativas, por ello: «Los poderes públicos de la Comunidad Autónoma del País Vasco asumen como función de interés social la promoción, estímulo y desarrollo de las entidades cooperativas y sus estructuras de integración empresarial y representativa»).

Es también destacable que las cooperativas practican una asepsia ideológica que les permite mantenerse en cualquier medio, favorable $u$ hostil, estando esa independencia ideológica asentada en el ADN del cooperativismo, lo que les ha facilitado históricamente su mantenimiento en toda clase de circunstancias.

Por todo ello, ante las adversidades económicas, ante la pérdida de empleos y ante el desánimo generalizado, las cooperativas bien merecen el respaldo social y las ayudas públicas para su mantenimiento y para el fomento de un sistema tan favorable para los intereses generales.

\section{Bibliografía}

KARL GRÜneWALD, «Relaciones económicas inter.-cooperativas». Intercoop. Buenos Aires, 1967.

CírCulo de EMPRESARIOS, "España ante el nuevo paradigma de la competitividad». Madrid, 2005.

Sara González Fernández, «La deslocalización de las empresas europeas hacia Latino América como estrategia comercial». Universidad Complutense. Cátedra Jean Monet. Madrid, 2004.

Rafael Mrro y Carlos Manuel Fernández-Otheo, «Deslocalización de empresas en España». Universidad Complutense. Madrid, 2005.

PriceWATERHOUSE CoOper España, «Encuesta sobre la deslocalización de empresas en España». Madrid, 2005.

Centro de Estudios Europeos para la Formación de los Trabajadores, "Actas del Seminario de Girona sobre deslocalización de empresas». Girona, 2009.

Revista TRABAJO Y UNIÓN (T.U. LANKIDE), Editorial, octubre de 2008. Mondragón, 2008.

Andoni GarcíA, «El Polo Tecnológico Garaia y la Innovación». Revista Cuadernos de Economía Social, número 4, 2008.

E.S. Bogardus, «Principles of Cooperation: The Cooperative League of the

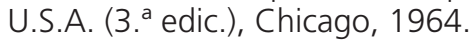


HANS-HÜNKNER, «Principios Cooperativos y Derecho Cooperativo», Bonn, 1988.

Diva Benevides PINHo, «Evolución del Pensamiento Cooperativista», Intercoop, Buenos Aires, 1987.

Bernard LAVERGNE, «El socialismo con rostro humano», Intercoop, Buenos Aires, 1985.

Gabriele RACUGNo, «La Società Cooperativa» («Trattato di Diritto Commerciale», Sezione IV-Tomo 9), Giappichelli, Torino, 2006.

Juan Antonio Pedreño Frutos, "La Economía Social, un modelo socioeconómico más socialmente equilibrado e innovador», en La Economía Social en España, 2008/2009, CEPES, Madrid, 2009.

José Luis Rodríguez Zapatero, "La importancia de la Economía Social en el nuevo modelo productivo», en La Economía Social en España, 2008/2009, CEPES, Madrid, 2009.

Javier Divar Garteiz-AurreCOA, "Globalización y Democracia», Dykinson, Madrid, 2005. 